\title{
Optimisation of Patient Flow and Scheduling in an Outpatient Haemodialysis Clinic
}

\author{
S. C. Nwaneri ${ }^{1 *}$, J. O. Ezeagbor ${ }^{2}$, D. O. T. Orunsholu ${ }^{1}$, C. O. Anyaeche ${ }^{2}$ \\ ${ }^{1}$ Department of Biomedical Engineering, University of Lagos, Lagos, Nigeria. \\ ${ }^{2}$ Department of Industrial/Production Engineering, University of Ibadan, Ibadan, Nigeria.
}

\begin{abstract}
The demand for renal replacement therapy (RRT) from the growing number of patients suffering from chronic kidney disease (CKD) and end stage renal disease (ESRD) in Nigeria is reported to be on the rise. However, dialysis clinics are few with limited facilities to meet the increasing demand leading to congestion, long waiting time and increased length of stay (LOS) in dialysis clinics. This paper presents an optimisation model for scheduling patient flow in an outpatient haemodialysis clinic. The objective is to minimize patient LOS using Genetic Algorithm (GA), implemented in Python programming language with Spyder Integrated Development Environment (IDE). The model was tested using data obtained from a haemodialysis clinic, in Lagos, Nigeria. The model generated optimum LOS values (193.01, 275.02 and 390.01) minutes compared to the mean LOS values at the haemodialysis clinic (235.50, 296.62 and 424.50) minutes for the 3-hour, 4-hour and 6-hour dialysis sessions. Furthermore, a simulation experiment of patient flow in a typical haemodialysis clinic was performed by gradual variations in patient arrival rates, $\lambda$. Simulation results at $(\lambda=0.1,0.2,0.3,0.4)$ revealed mean $\operatorname{LOS}$ (minutes) as $(312.85 \pm 73.45,348.18 \pm 84.89,342.18$ $\pm 81.30,305,28 \pm 63.67$ ) respectively. The optimisation model was effective in reducing patient LOS.
\end{abstract}

KEYWORDS: Dialysis; Genetic Algorithm; Optimisation; Patient Scheduling; Simulation.

\section{INTRODUCTION}

Haemodialysis is the most common renal replacement therapy (RRT) for patients suffering from chronic kidney disease (CKD) and end-stage renal disease (ESRD) in lowand-middle income countries (LMICs) (Bamgboye, 2003). The machine uses a dialyzer to eliminate metabolic wastes from the blood based on the principle of diffusion (Man et al., 1995). Unfortunately, lack of access to treatment accounts for high mortality from both CKD and ESRD estimated at over 2.3 million deaths (Liyanage et al., 2015). In addition to this, dialysis is overly expensive which is aggravated by the need for patients to undergo dialysis frequently. Usually, patients are frequently dialysed for about three times a week. (Adejumo et al., 2017; Chan et al., 2019).

Furthermore, only few haemodialysis centres are available in LMICs. With increased demand for dialysis, congestion and delays are common in the few functional dialysis centres available eventually leading to long waiting time and length of stay (LOS) which are significant determinants of patient satisfaction and quality of care (Ho et al., 2006; Ahsan et al., 2019). Extended LOS in haemodialysis clinics often leads to poor functional outcomes and reduction in the number of haemodialysis sessions (Collins et al., 2010; Liu et al., 2017). Also, most dialysis centres have no *Corresponding author: snwaneri@unilag.edu.ng structured policy and strategies for efficient patient scheduling (Jafar et al., 2020). Consequently, effective optimisation of patient flow and scheduling has become necessary (Odubanjo et al., 2011; Ajayi et al., 2016). In a typical haemodialysis clinic, the patient needs to undergo various processes that often lead to long waiting times and LOS (Choi et al., 2017). Patients may be served based on any of the following queuing policies including first-come first served (FCFS), last-come first served (LCFS), service in random order (SIRO), round robin service (RRS) and priority service (Ayandele and Nnamseh, 2012). However, FCFS is the preferred queuing policy in most haemodialysis clinics largely due to its simplicity. Industrial and systems engineering strategies have been widely applied in health systems improvement as well reported in literature (Fei et al., 2010; Lee et al., 2013; Nwaneri and Anyaeche, 2018). However, few studies have developed optimisation models for haemodialysis scheduling (Afrane and Appah, 2014; Choi et al., 2017). Choi et al., (2017) modeled an ESRD problem with various dialysis conditions using a variable-volume two-compartment kinetic model and used Genetic Algorithm (GA) to find the optimal haemodialysis schedule for each individual. There is need to determine the optimal combination of processes that will minimise LOS in a typical haemodialysis clinic.

doi: http://dx.doi.org/10.4314/njtd.v18i2.6 
Therefore, the optimisation of an outpatient haemodialysis schedule is the main thrust of this paper. The model was also expected to provide a framework to improve the efficiency of patient flow in a typical haemodialysis clinic. Optimisation and efficient planning of processes in haemodialysis centres is perceived to significantly reduce LOS and improve patient flow (Forrest et al., 2005; Kainzinger et al., 2009; Karkar et al., 2015). The remaining sections of this paper are structured as follows: Literature is reviewed in section II; the methodology is described in section III. The research results and discussion are presented in sections IV and V respectively and the conclusion in section VI closes the paper.

\section{LITERATURE REVIEW}

Optimisation of patient flow and scheduling in hospitals have received considerable research attention (Augusto et al., 2010; Fleming et al., 2019). Various analytical and heuristic optimisation strategies have been proposed to improve scheduling in healthcare systems including the use of Lagrangian relaxation-based methods (Augusto et al., 2010), Column generation based heuristic procedure (Fei et al., 2010), simulation models (Lee et al., 2013). These models may be constrained or unconstrained. Constrained optimisation methods have been widely used in healthcare to improve various processes by including patient scheduling. In a study to address resource allocation and outpatient appointment scheduling problems, Lin et al., (2017) proposed an approach based on a multiphase and multi-server queuing system with stochastic factors in order to optimise the weighted objectives of patient waiting time, resource overtime and waiting room congestion. This method utilizes a two-stage simulation-based heuristic algorithm to assess various tactical and operational decisions for optimising the multiple objectives. In another study, Hribar et al., (2018) modeled an outpatient ophthalmology clinic workflow using discrete event simulation for testing new scheduling templates.

Fleming et al., (2018) developed an analytical method and a decision support tool for scheduling dialysis patients. Two objective functions were developed. While the first function was used to minimise the maximum waiting time for patients to start the dialysis process, the second objective function minimised the maximum scheduled finish time. Nappo and Ross (2020) used queuing theory principles to optimise schedules by including timing and workflow for every dialysis process step to design a new schedule. The study revealed improvements in facility efficiency and urea clearance reduction ratios. With the increased need for efficient scheduling of haemodialysis procedures and processes, innovative strategies should be deployed to minimise patient LOS. Most of the previous studies focused on the minimisation of patient waiting time (Bakker et al., 2016; Fleming et al., 2019).

The application of real-life data to minimise LOS in outpatient haemodialysis clinic is yet to be fully investigated. This study focused on developing a haemodialysis schedule optimisation model for an outpatient dialysis clinic. The development of scheduling optimisation model will enable the haemodialysis unit to manage their resources more efficiently, and to minimise treatment delays and avoid extending LOS of CKD and ESRD patients on dialysis due to various complications. Also, the study includes the simulation of patient flow to mimic real-life dialysis processes.

\section{METHODOLOGY}

\section{A. Problem Description and Formulation}

The process starts with the arrival of patients to the clinic. In a typical haemodialysis clinic, patients undergo several processes classified in this study as pre-dialysis, dialysis and post-dialysis sessions. Pre-dialyses processes include the examination of patients for signs of Oedema followed by vital signs and weight measurement. Pre-dialysis tests are performed to reveal the urea and creatinine levels of patients before dialysis. Dialysis is performed after patients are connected to the machine using any of the following access routes including femoral catheterization, fistulas and internal jugular (IJ) catheters. Standard haemodialysis procedures could last between 3 - 4 hours and 6 hours for patients that need sustained low efficient dialysis (SLED) (Sethi et al., 2018).

Post-dialysis processes include measurement of post disconnection vitals, post dialysis radiology and laboratory testing, post-dialysis consultation and collection of drugs at pharmacy. Not all patients pass through all the processes in the post-dialysis stages. For instance, a patient who has not exhausted his drugs may not need to visit the pharmacy. The effectiveness of the dialysis process is evaluated by postdialysis laboratory tests. The study was performed with data obtained from a private haemodialysis clinic in Lagos, Nigeria. Treatment was based on a 'First Come, First Served' (FCFS) and preferential treatments were only given to emergency cases. The entire process is clearly depicted in Figure 1 which describes the clinical arrangement and patient flow for a dialysis operation at the clinic. The haemodialysis clinic used as case study has two rooms dedicated for haemodialysis procedures. There are five machines in each room with identical amenities. The rooms are equipped with electrically adjustable chairs for patients and a water treatment unit that has the capacity to power a maximum of 5 dialysis machines. A minimum of two dialysis nurses are assigned to each room as well as a dialysis technician who provides technical support for the equipment.

The problem is formulated as a single objective optimisation model and described as follows: Consider a haemodialysis clinic with $\mathrm{N}$ number of patients, each patient $p$, is treated using a given treatment option $j$. The patient $p$ undergoes several processes within a given duration including pre-dialysis time $P_{t p}$, dialysis time, $D_{t p}$ and post-dialysis time, $P D_{t p}$. The problem is to determine the optimal combination of $P_{t p}, D_{t p}$, and $P D_{t p}$, that seeks to minimise the patient's length of stay, LOS. A mathematical model was developed to minimise patient LOS in a typical haemodialysis clinic. The mathematical notations used in this paper are presented in Table 1. 


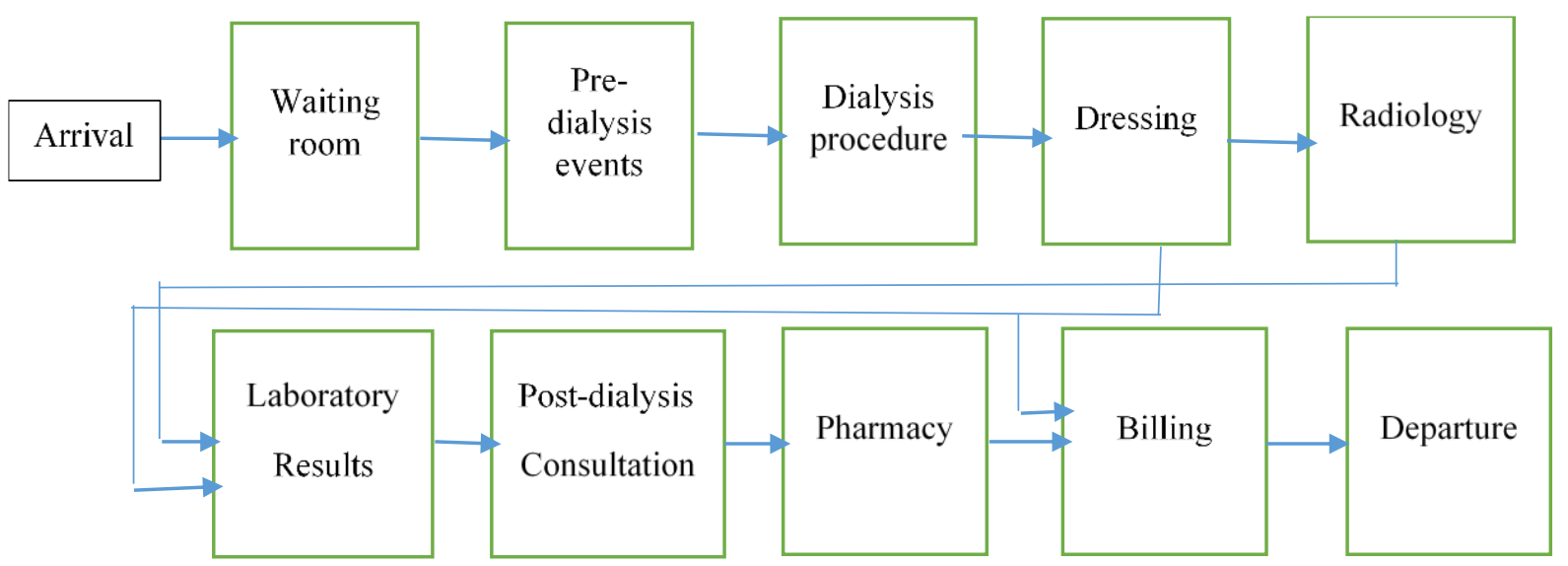

Figure 1: Workflow of Haemodialysis process.

Table 1: Mathematical notations.

\begin{tabular}{ll}
\hline Notation & Description \\
\hline $\boldsymbol{A}_{\boldsymbol{t}}$ & Arrival time \\
$\boldsymbol{P}_{\boldsymbol{t} p}$ & Pre-dialysis time of patient $\mathrm{p}$ \\
$\boldsymbol{D}_{\boldsymbol{t} p}$ & Dialysis duration for patient $\mathrm{p}$ \\
$\boldsymbol{D}_{\boldsymbol{r}}$ & Regular time for dialysis (4 hours) \\
$\boldsymbol{D}_{\boldsymbol{s}}$ & Dialysis time for SLED (6 hours) \\
$\mathbf{W}_{\mathbf{t p}}$ & Waiting time of patient $\mathrm{p}$ \\
$\mathbf{P D}_{\mathbf{t p}}$ & Post-dialysis time for patient $\mathrm{p}$ \\
LOS & Total length of stay \\
$\mathrm{N}$ & Maximum number of patients arriving \\
$\mathbf{D}_{\mathbf{t}}$ & Departure time \\
$\mathrm{D}$ & Dialysis block \\
$\mathbf{x}_{\mathbf{p j}}$ & Index variable of patient p, when treated using \\
& access route option $\mathrm{j}$; if $x_{p j}=1$ then patient $\mathrm{p}$ was \\
& treated using the jth option, or otherwise if $x_{i j}=0$ \\
\hline
\end{tabular}

The model was developed based on the following assumptions:

i. Patients are served on arrival.

ii. The number of operating hours and medical resources are fixed.

iii. The number of dialysis stations are fixed.

iv. Non-dialysis procedures may be delayed to accommodate the dialysis treatment.

v. Delays between processes are neglected.

vi. Delays in the process due to emergencies are neglected.

\section{B. Model objective function}

The objective function is formulated as:

$$
\text { Min LOS }=\sum_{\mathrm{p}}^{\mathrm{n}}\left(\mathrm{P}_{\mathrm{tp}}+\mathrm{D}_{\mathrm{tp}} \mathrm{x}_{\mathrm{pj}}+\mathrm{PD}_{\mathrm{tp}}\right)
$$

Subject to the constraints:

$$
\begin{aligned}
& \sum_{\mathrm{d}=1}^{\mathrm{m}} \mathrm{x}_{\mathrm{pj}}=1, \forall p \\
& L O S \leq D_{t}, \forall d \\
& A_{t}<D_{t}
\end{aligned}
$$

In this model, Eq. (1) minimizes the total LOS for each patient. The first constraint limits dialysis on each patient to one unit only. The second constraint ensures that the total completion time of each unit is less than the patient departure time. The third constraint ensures arrival time is less than departure time.

\section{Model Implementation}

The model was implemented using Genetic Algorithm (GA). GA is an adaptive evolutionary search optimisation technique that operates based on the principles of natural selection and natural genetics (Chiesa et al., 2020). Characteristically, GA works by generating a random population of individuals (parents) used to encode the solutions as chromosomes which consist of genes. The individuals reproduce and exchange genes with the offspring selected based on their level of fitness. The process is repeated until optimal solutions are generated. The procedure for GA implementation is clearly explained in literature (Goldberg, 1989; Hegazy, 1999; Bajpai and Kumar, 2010).

In this paper, the algorithm was implemented using Python programming language (Python 3.7.4) in Spyder integrated development environment (IDE) platform. Python was chosen because it is an open-source programming software with vast support libraries that enable model optimisation (Bakker et al., 2016). The algorithm is implemented by importing numerical python package (Numpy) and GA in Python. Objective function was defined using Eq. (1). Decision variable were selected which are $\mathrm{P}_{\mathrm{tp}}$, $\mathrm{D}_{\mathrm{tp}}$, and $\mathrm{PD}_{\mathrm{tp}}$. Boundaries for the decision variables were set with the minimum and maximum values from each decision variable in Table 3 set as lower and upper limits respectively. Since the variables are continuous values, 'real variable types' were selected. Afterwards, the default GA parameters in Python were modified. A population size of 100, maximum iterations of 1000 , mutation probability of 0.1 , crossover probability of 0.5 and uniform crossover type were selected as shown in Table 2. 
Table 2: Genetic Algorithm Parameters.

\begin{tabular}{lc} 
Parameter & Value \\
\hline Population size & 100 \\
Maximum iterations & 1000 \\
Mutation probability & 0.1 \\
Crossover probability & 0.5 \\
Crossover type & uniform \\
\hline
\end{tabular}

The pseudocode for the GA is summarized as shown in Figure 2 . The scheduling time of various processes including the arrival and departure time, pre-dialysis, dialysis and postdialysis activities are shown in Appendix A.

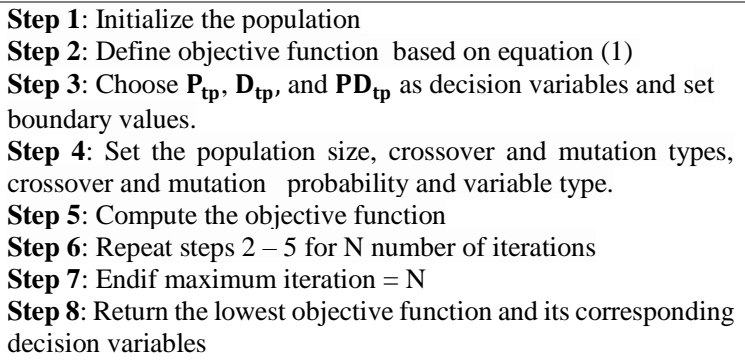

Figure 2: Pseudocode for Genetic Algorithm.

\section{Simulation of Patient Flow in a Haemodialysis Clinic}

Patient flow in the haemodialysis clinic was further simulated using the SimPy discrete-event simulation Python library. It utilises queuing theory, a scientific theory that has been widely applied in a variety of service industries including healthcare to develop models that predict the behaviour of systems in a situation characterised by random demands for services (Gross et al., 2008). A G/G/10 queue is proposed and assumed to be based on finite queuing situation. Patient arrival is based on Poisson arrival distribution with a mean arrival rate, $\lambda=0.1$ patients per minute computed as:

$$
a=\frac{1}{\lambda}
$$

For the service rates, 3 different service rates are adopted for the 3 stages of service. Service rate for pre-dialysis stage is exponentially distributed with probability density function computed as:

$$
p=\frac{1}{\mu} e^{-\frac{1}{\mu} t}
$$

where $\mu=$ mean pre-dialysis time

For dialysis, the service rate is randomly selected from dialysis duration, $d=[180,240$ and 360] minutes. While the post-dialysis stage is exponentially distributed with probability density function computed with Eq. (6). The algorithm for the simulation of haemodialysis processes is shown in Figure 3.

\author{
Step 1: Set $\mathbf{A}_{\mathbf{t}}$, mean $\mathbf{P}_{\mathrm{tp}}, \mathbf{D}_{\mathrm{tp}}$ and $\mathbf{P} \mathbf{D}_{\mathrm{tp}}$ values \\ Step 2: Generate haemodialysis patients according to \\ Poisson distribution. Initialize patients created. \\ Step 3: While (patients generated $<N$ ), generate next $\lambda$, \\ service rates for pre-dialysis, dialysis and post- dialysis \\ duration of each patient. \\ Step 4: Generate bed request and release for each patient \\ Step 5: Compute LOS for each patient using equation (1) \\ Step 6: End While
}

Figure 3: Algorithm for simulation of haemodialysis processes.

\section{RESULTS AND DISCUSSION}

\section{A. Results of Genetic Algorithm Optimisation}

According to Table 3, the percentage of patients dialysed in 3-hour, 4-hour and 6-hour dialysis sessions respectively were $21 \%, 74 \%$ and $5 \%$ respectively. Similarly, the mean post-dialysis procedures computed from Appendix A, for the 3-hour, 4-hour and 6-hour dialysis sessions occurred in 47.08 minutes, 46 minutes and 65 minutes respectively. The GA improved consistently the LOS for all the sessions. Accordingly, the objective function values represent the proportions of time spent across the process entirely.

Table 3 shows the results of testing real-life data from the haemodialysis clinic on model. Accordingly, the objective function which represents the LOS values was optimised and gave optimum LOS values of 193.01 minutes, 275.02 minutes and 390.01 minutes from the corresponding pre-dialysis, dialysis and post-dialysis time used as decision variables for the 3-hour, 4-hour and 6-hour dialysis sessions as shown in Figures 3 and 4, respectively. Further representation of the results in Figures $4-6$ reveal a general improvement in the objective function with increased iterations.

Table 3: Best solutions.

\begin{tabular}{lcccc}
\hline Option & $\begin{array}{l}\text { Pre- } \\
\text { dialysis } \\
\text { (min) }\end{array}$ & $\begin{array}{l}\text { Dialysis } \\
\text { (min) }\end{array}$ & $\begin{array}{l}\text { Post- } \\
\text { dialysis } \\
\text { (min) }\end{array}$ & $\begin{array}{l}\text { Objective } \\
\text { Function }\end{array}$ \\
\hline $\begin{array}{l}\text { 3-hour dialysis } \\
\text { session }\end{array}$ & 3.00 & 180.01 & 10.03 & 193.04 \\
$\begin{array}{l}\text { 4-hour dialysis } \\
\text { session }\end{array}$ & 10.00 & 240.00 & 25.02 & 275.02 \\
$\begin{array}{l}\text { 6-hour dialysis } \\
\text { session }\end{array}$ & 20.00 & 340.00 & 30.00 & 390.01 \\
\hline
\end{tabular}

Performance comparison of the mean LOS values which are real life data obtained from the haemodialysis clinic and optimised values of LOS shown in Table 4 suggests a considerable improvement in the LOS achieved from optimisation. For the 3-hour, 4-hour and 6-hour dialysis procedures, the mean LOS reduced from 235.50 to 193.04; 296.62 to 275.02 and 424.50 to 390.01 minutes respectively. This demonstrates the utility of the model suggesting that the planned dialysis procedures are useful (Forrest et al., 2005). 


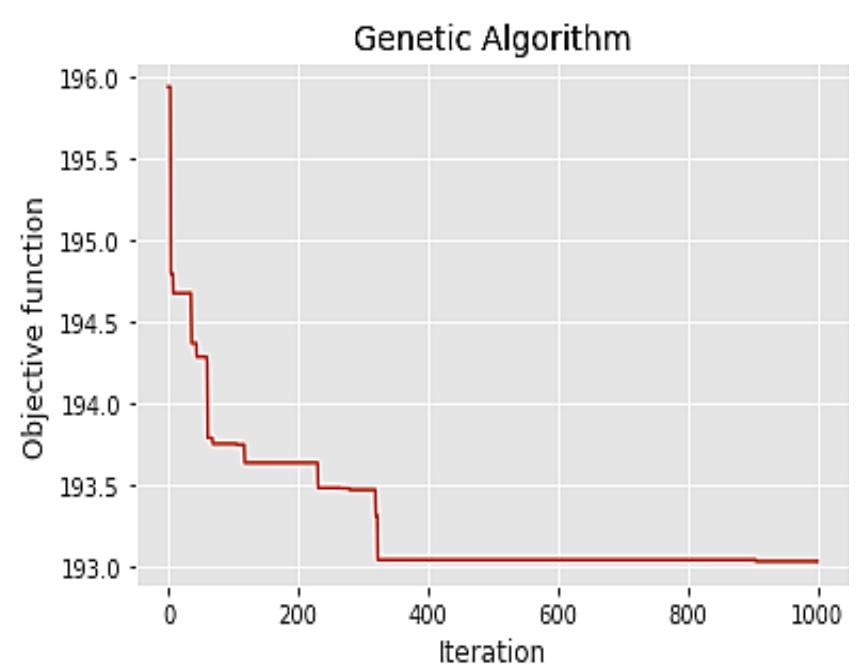

Figure 4: Length of Stay for 3-hour dialysis session.



Figure 5: Optimised Length of Stay for 4-hour dialysis session.

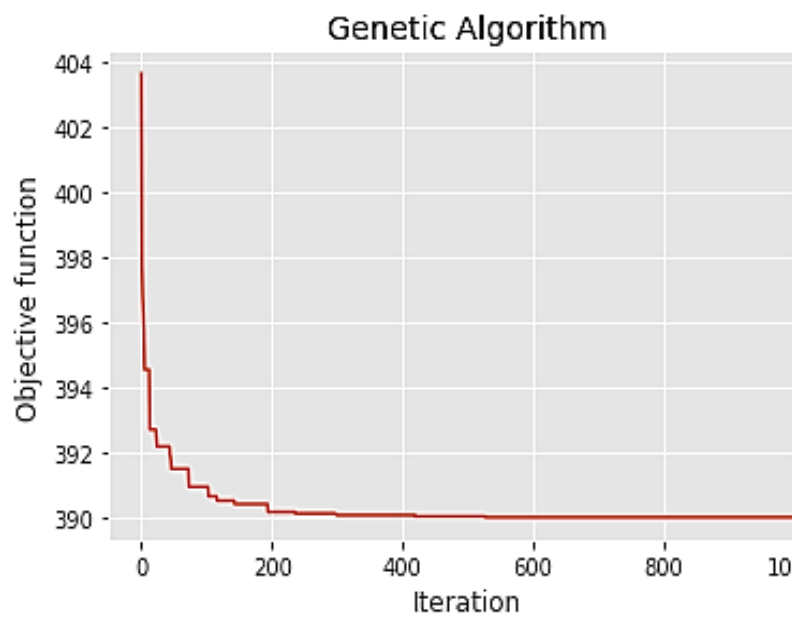

Figure 6. Optimised Length of Stay for 6-hour dialysis session.
Table 4: Performance Comparison of Mean LOS of Haemodialysis Clinic and Optimised LOS.

\begin{tabular}{cccc}
\hline Option & $\begin{array}{l}\text { Mean LOS of } \\
\text { Haemodialysis } \\
\text { Clinic (minutes) }\end{array}$ & $\begin{array}{l}\text { Optimised } \\
\text { LOS of the } \\
\text { model } \\
\text { (minutes) }\end{array}$ & $\begin{array}{l}\text { Standard } \\
\text { Deviation }\end{array}$ \\
\hline 3-hour & 235.50 & 193.04 & 27.64 \\
4-hour & 296.62 & 275.02 & 18.36 \\
6-hour & 424.50 & 390.01 & 18.70 \\
\hline
\end{tabular}

\section{B. Results of Model Simulation}

Simulation experiments were performed with interarrival rates set at $=0.1, \lambda=0.2, \lambda=0.3$ and $\lambda=0.4$ with the results shown in Tables $6-9$ respectively. The start times for pre-dialysis events which represent pre-connection procedures were performed at fixed intervals. The duration for pre-dialysis events varies randomly from one patient to the other which typically depicts what happens in real-life situations. Also, the dialysis duration of each patient is randomly selected from the three options available that last for 180,240 and 360 minutes. We found from the results in Tables $5-8$ that the LOS is mostly affected by the duration of the dialysis and post-dialysis procedures but not by the arrival time. Consequently, a reduction in LOS could be achieved by improving the efficiencies of the dialysis and post-dialysis procedures. In particular, specific improvement by increasing manpower or equipment as well as the processes in postdialysis activities such as radiology, laboratory tests, and pharmacy could lead to a reduction in LOS but a corresponding increase in cost. The management may need to take a trade-off decision depending on their preferences.

Table 9 shows the comparison of simulation results for the different arrival rates. The mean LOS for all mean arrival rates in this study range from 305.28 minutes to 348.18 minutes. At $\lambda=0.4$, the mean \pm standard deviation of the LOS, was minimal (305.28 \pm 63.67$)$ minutes. We found no significant differences between the means and standard deviations of the LOS for the different arrival rates. The implication of this for a haemodialysis clinic is that the system can be optimised to use less resources at the pre-dialysis stage by scheduling patient arrivals at short intervals to avoid congestion in the system. Overall, careful planning of the operations of the haemodialysis clinic is necessary as it could lead to cost minimisation and increased efficiency of the system. The results suggest that with a well-planned scheduling strategy, patients' LOS in haemodialysis clinics could be improved. Our findings are in agreement with similar studies which demonstrated the effectiveness of optimisation tools in planning haemodialysis processes (Stecz et al., 2019).

Furthermore, the simulation of patient flow for a typical haemodialysis clinic modeled to reflect the real-life peculiarities by incorporating uncertainty in patient arrival rate showed interesting results. We observed no significant difference in the means and standard deviations of the LOS for the different patient interarrival rates. The implication of this for a haemodialysis clinic is that the system can be optimised to use less resources at the pre-dialysis stage by 
Table 5: Simulation results $(\lambda=0.1)$.

\begin{tabular}{cccccccc}
\hline Patient & \multicolumn{2}{c}{ Pre-dialysis } & \multicolumn{2}{c}{ Dialysis } & \multicolumn{2}{c}{ Post-dialysis time } & Total LOS \\
& Start time & Finish time & Start time & Finish time & Start & Finish time & \\
time & & & & & \\
Patient 1 & 0.00 & 7.53 & 7.53 & 367.53 & 367.53 & 372.17 & 372.17 \\
Patient 2 & 10.00 & 12.42 & 12.42 & 193.42 & 193.42 & 223.01 & 213.01 \\
Patient 3 & 20.00 & 23.73 & 23.73 & 383.75 & 383.75 & 505.61 & 485.61 \\
Patient 4 & 30.00 & 35.37 & 35.37 & 215.37 & 215.37 & 286.09 & 256.09 \\
Patient 5 & 40.00 & 43.24 & 43.24 & 283.24 & 283.24 & 352.17 & 312.17 \\
Patient 6 & 50.00 & 64.21 & 64.21 & 244.21 & 244.21 & 311.94 & 261.94 \\
Patient 7 & 60.00 & 63.44 & 63.44 & 423.44 & 423.44 & 424.17 & 364.17 \\
Patient 8 & 70.00 & 70.24 & 70.24 & 250.24 & 250.24 & 350.73 & 280.73 \\
Patient 9 & 80.00 & 95.66 & 95.66 & 275.66 & 275.66 & 381.82 & 301.82 \\
Patient 10 & 90.00 & 93.18 & 93.18 & 333.18 & 333.18 & 370.77 & 280.77 \\
\hline
\end{tabular}

Table 6: Simulation results $(\lambda=0.2)$.

\begin{tabular}{|c|c|c|c|c|c|c|c|}
\hline \multirow[t]{2}{*}{ Patient } & \multicolumn{2}{|c|}{ Pre-dialysis } & \multicolumn{2}{|c|}{ Dialysis } & \multicolumn{2}{|c|}{ Post-dialysis time } & \multirow{2}{*}{$\begin{array}{l}\text { Total } \\
\text { LOS }\end{array}$} \\
\hline & $\begin{array}{l}\text { Start } \\
\text { time }\end{array}$ & $\begin{array}{c}\text { Finish } \\
\text { time }\end{array}$ & $\begin{array}{l}\text { Start } \\
\text { time }\end{array}$ & $\begin{array}{l}\text { Finish } \\
\text { time }\end{array}$ & $\begin{array}{l}\text { Start } \\
\text { time }\end{array}$ & $\begin{array}{l}\text { Finish } \\
\text { time }\end{array}$ & \\
\hline Patient 1 & 0.00 & 7.53 & 7.53 & 247.53 & 247.53 & 252.17 & 252.17 \\
\hline Patient 2 & 5.00 & 7.42 & 7.42 & 247.42 & 247.42 & 278.01 & 273.01 \\
\hline Patient 3 & 10.00 & 13.75 & 13.75 & 373.75 & 373.75 & 495.61 & 485.61 \\
\hline Patient 4 & 15.00 & 20.37 & 20.37 & 260.37 & 260.37 & 331.09 & 316.09 \\
\hline Patient 5 & 20.00 & 23.24 & 23.24 & 203.24 & 203.24 & 272.17 & 252.17 \\
\hline Patient 6 & 25.00 & 39.21 & 39.21 & 399.21 & 399.21 & 466.94 & 441.94 \\
\hline Patient 7 & 30.00 & 33.44 & 33.44 & 393.44 & 393.44 & 394.17 & 364.17 \\
\hline Patient 8 & 35.00 & 35.24 & 35.24 & 395.24 & 395.24 & 495.73 & 460.73 \\
\hline Patient 9 & 40.00 & 55.66 & 55.66 & 295.66 & 295.66 & 401.82 & 361.82 \\
\hline Patient 10 & 45.00 & 48.18 & 48.18 & 288.18 & 288.18 & 319.05 & 274.05 \\
\hline
\end{tabular}

Table 7: Simulation results $(\lambda=0.3)$.

\begin{tabular}{cccccccc}
\hline Patient & \multicolumn{2}{c}{ Pre-dialysis } & \multicolumn{2}{c}{ Dialysis } & \multicolumn{2}{c}{ Post-dialysis time } & Total \\
& \cline { 2 - 5 } & Start time & $\begin{array}{c}\text { Finish } \\
\text { time }\end{array}$ & $\begin{array}{c}\text { Start } \\
\text { time }\end{array}$ & $\begin{array}{c}\text { Finish } \\
\text { time }\end{array}$ & $\begin{array}{c}\text { Start } \\
\text { time }\end{array}$ & $\begin{array}{c}\text { Finish } \\
\text { time }\end{array}$ \\
\hline Patient 1 & 0.00 & 7.53 & 7.53 & 247.53 & 247.53 & 252.17 & 252.17 \\
Patient 2 & 3.33 & 5.75 & 5.75 & 245.75 & 245.75 & 276.35 & 273.02 \\
Patient 3 & 6.67 & 10.42 & 10.42 & 370.42 & 370.42 & 492.28 & 485.61 \\
Patient 4 & 10.00 & 15.37 & 15.37 & 375.37 & 375.37 & 446.09 & 436.09 \\
Patient 5 & 13.33 & 16.57 & 16.57 & 376.57 & 376.57 & 445.50 & 432.17 \\
Patient 6 & 16.67 & 30.88 & 30.88 & 210.88 & 210.88 & 278.60 & 261.93 \\
Patient 7 & 20.00 & 23.44 & 23.44 & 383.44 & 383.44 & 384.17 & 364.17 \\
Patient 8 & 23.33 & 23.57 & 23.57 & 203.97 & 203.97 & $304 / 07$ & 280.74 \\
Patient 9 & 26.67 & 42.33 & 42.33 & 282.33 & 282.33 & 388.49 & 361.82 \\
Patient 10 & 30.00 & 33.18 & 33.18 & 273.18 & 273.18 & 304.05 & 274.05 \\
\hline
\end{tabular}

Table 8: Simulation results $(\lambda=0.4)$.

\begin{tabular}{|c|c|c|c|c|c|c|c|}
\hline \multirow[t]{2}{*}{ Patient } & \multicolumn{2}{|c|}{ Pre-dialysis } & \multicolumn{2}{|c|}{ Dialysis } & \multicolumn{2}{|c|}{ Post-dialysis time } & \multirow[t]{2}{*}{ Total LOS } \\
\hline & Start time & $\begin{array}{l}\text { Finish } \\
\text { time }\end{array}$ & $\begin{array}{l}\text { Start } \\
\text { time }\end{array}$ & $\begin{array}{c}\text { Finish } \\
\text { time }\end{array}$ & $\begin{array}{l}\text { Start } \\
\text { time }\end{array}$ & $\begin{array}{c}\text { Finish } \\
\text { time }\end{array}$ & \\
\hline Patient 1 & 0.00 & 7.53 & 7.53 & 367.53 & 367.53 & 372.17 & 372.17 \\
\hline Patient 3 & 5.00 & 8.75 & 8.75 & 188.75 & 188.75 & 310.61 & 305.61 \\
\hline Patient 4 & 7.50 & 12.87 & 12.87 & 372.87 & 372.87 & 443.59 & 436.09 \\
\hline Patient 5 & 10.00 & 13.24 & 13.24 & 373.24 & 373.24 & 373.24 & 363.24 \\
\hline Patient 7 & 15.00 & 18.44 & 18.44 & 258.44 & 258.44 & 259.17 & 244.17 \\
\hline Patient 8 & 17.50 & 17.74 & 17.74 & 197.74 & 197.74 & 298.23 & 280.73 \\
\hline Patient 9 & 20.00 & 35.67 & 35.67 & 215.67 & 215.67 & 321.82 & 301.82 \\
\hline Patient 10 & 22.50 & 25.68 & 25.68 & 205.68 & 205.68 & 236.55 & 214.05 \\
\hline
\end{tabular}

Table 9: Comparison of simulation results.

\begin{tabular}{ccc}
\hline Mean Arrival Rate $(\boldsymbol{\lambda})$ & Mean LOS & Standard Deviation \\
\hline 0.1 & 312.85 & 73.45 \\
0.2 & 348.18 & 84.49 \\
0.3 & 342.18 & 81.30 \\
0.4 & 305.28 & 63.67 \\
\hline
\end{tabular}


scheduling patient arrivals at short intervals to avoid congestion in the system. Overall, careful planning of the operations of the haemodialysis clinic is necessary as it could lead to cost minimisation and increased efficiency of the system.

Finally, the results also suggest that a few patients seeking emergency haemodialysis services can be accommodated for dialysis procedures that last for $2-3$ hours without causing much disruption to the system. The high rates of patients seeking emergency haemodialysis procedures is a research problem of significant public health concern (Zhang et al., 2019). With minor adjustments in the schedule of regular patients expected to arrive at a short interval, unscheduled emergency patients can be treated.

\section{CONCLUSION}

In this paper, a haemodialysis schedule optimisation model was developed to reduce patient length of stay. Due to the increased demand for dialysis from CKD and ESRD patients in Nigeria, there is need to improve the processes in the few available clinics with limited facilities to reduce congestion, long waiting time and increased LOS. The model was realized in Python using GA. We compared the performance of the model with the mean LOS at the haemodialysis clinic used as case study and found that the optimised model showed better performance compared to the mean LOS at the clinic. The model was therefore effective in reducing patients LOS. Further simulation of patient flow in a typical haemodialysis clinic with small variations in patient interarrival rate revealed no significant differences in LOS. We also found that the LOS was mostly determined by the duration of dialysis procedure rather than the arrival time when patient arrival rates are at closely spaced intervals.

\section{REFERENCES}

Adejumo, A. O.; J.D. Olusoji and F.O. Andrew. (2017). Factors associated with TB/HIV co-infection among drug sensitive tuberculosis patients managed in a secondary health facility in Lagos, Nigeria. African Journal of Infectious Diseases, 11(2): 75 - 82.

Afrane, S. and Appah, A. (2014). Queuing theory and the management of waiting-time in hospitals: The case of Anglo Gold Ashanti Hospital in Ghana. International Journal of Academic Research in Business and Social Sciences, 4(2):34 $-44$.

Ajayi S.; Y. Raji; T. Bello; L. Jinadu and B. Salako (2016). Unaffordability of renal replacement therapy in Nigeria. Hong Kong Journal of Nephrology, 18:15 - 18.

Augusto V.; X. Xie and V. Perdomo (2010). Operating theatre scheduling with patient recovery in both rooms and recovery beds. Computers and Industrial Engineering, 58:231 -238 .

Ayandele, I.A. and Nnamseh, M.P. (2012). Healthcare Service Delivery: The Queuing theory approach. International Journal of Social Sciences and Humanities Reviews, 3(3): 51 -64 .

Bajpai, P. and Kumar, M. (2010). Genetic algorithm an approach to solve global optimisation problem. Indian
Journal of Computer Science and Engineering, 1(3):199 206.

Bakker M.; V. Post; C. D. Langevin; J. D. Hughes; J. T. White; J. J. Starn; M. N. Fienen. (2016). Scripting MODFLOW model development using Python and Floppy. Groundwater, 54(5):733 - 739 .

Bamgboye, E. (2003). Haemodialysis: Management Problems in Developing Countries, with Nigeria as a Surrogate. Kidney International, Supplement 63(83): S93S595.

Chan C.T.; P.J. Blankestin; L.M. Dember; M. Gallieni; D.C.H. Harris; et al., (2019). Dialysis initiation, modality choice, access, and prescription. Kidney International Journal, 96:37 - 47.

Chen B.; E. Li; Y. Kazunobu; K. Ken; N. Shinji and W. Miao (2010). Impact of adjustment measures on reducing outpatient waiting time in a community hospital: application of a computer simulation. Chinese Medical Journal, 123(5):574 - 580.

Chiesa M.; G. Maioli; G.I. Colombo and L. Piacentini (2020). GARS: Genetic Algorithm for the identification of a Robust Subset of features in high-dimensional datasets. Available online at: https://bmcbioinformatics.biomedcentral.com/articles/10.118 6/s12859-020-3400-6. Accessed on March 20, 2020.

Collins N.J.; K.M. Crossley; R. Darnell; et al. (2010). Predictors of short- and long-term outcome in patellofemoral pain syndrome: a prospective longitudinal study. Available online

at:

https://bmcmusculoskeletdisord.biomedcentral.com/articles/1 0.1186/1471-2474-11-11. Accessed on March 21, 2020.

Fei H.; N. Meskens and C. Chu (2010) A planning and Scheduling problem for an operating theatre using an open scheduling strategy. Computers and Industrial Engineering, 58: $221-230$.

Fleming R.; D. Gartner; R. Padman and D. James. (2019). Analytic approach for improving patient-centric delivery of dialysis services. AMIA Annual Symposium Proceedings Archives, 418 -427.

Forrest G.; M. Nagao; A. Iqbal and R. Kakar (2005). Inpatient rehabilitation of patients requiring haemodialysis: improving efficiency of care. Archives of Physical Medicine, 86(10): 1949 - 1952.

Goldberg, D.E. (1989). Genetic Algorithms in Search. Optimization and Machine Learning. Addison Wesley, New York, USA.

Gross D.; J.F. Shortie; J.M. Thompson and C.M. Harris (2008). Fundamentals of Queueing Theory. Fourth Edition, John Wiley \& Son, New Jersey, USA.

Jafar T.H.; R.C. John; O. Tewari A. Cobb B. LegidoQuigley Y. Sungwon and V. Jha (2020). Access to CKD Care in Rural Communities of India: a qualitative study exploring the barriers and potential facilitators. Available online

at: https://bmcnephrol.biomedcentral.com/articles/10.1186/s1 2882-020-1702-6. Accessed on March 21, 2020.

Hegazy, T. (1999). Optimisation of resource allocation and leveling using genetic algorithm. Journal of Construction Engineering and Management, 167 -175. 
Horn S.; P. Buerhaus; N. Bergstrom and R. Smout (2005). RN Staffing Time and Outcomes of Long-Stay Nursing Home Residents: Pressure ulcers and other adverse outcomes are less likely as RNs spend more time on direct patientcare. American Journal of Nursing, 105(11):58 -70.

Hribar M.R.; S. Read-Brown; L. Reznick and M.F. Chiang (2017). Evaluating and improving an outpatient clinic scheduling template using secondary electronic health record. AMIA Annual Symposium Proceedings Archives, 921 - 929.

Karkar A.; L. Dammang and M. Bouhaha (2015). Stress and burnout among haemodialysis nurses: a singlecentre, prospective survey study. Saudi Journal of Kidney Diseases and Transplantation, 26(1): $12-18$.

Lee S.; D. Min; J. Ryu and Y. Yih (2013). A simulation study of appointment scheduling in outpatient clinics: open access and overbooking. Simulation: Transactions of the Society for Modelling and Simulation International 89(12):1459-1473.

Lin K.Y.L.; T.W.C Ling and W.K. Yeung (2017). Resource allocation and outpatient appointment scheduling using simulation optimization. Available online at: https://doi.org/10.1155/2017/9034737. Accessed on March $28,2020$.

Liu Z.; L. Jiongbing; L. Zaisheng; L. Guangrui; Z. Hao and D. Junwu (2017). Patient scheduling in hemodialysis service. Available online at: https://link.springer.com/article/10.1007\%2Fs10878-0170232-z. Accessed on April 14, 2020.

Liyanage T.; T. Ninomiya; V. Jha; et al. (2015). World access to treatment for end-stage kidney disease: a systematic review. Lancet, 365:1975 - 1982.

Man N.K.; J. Zingraff and P. Jungers (1995). Basic Principles of Haemodialysis, In: Long-Term Hemodialysis. Available online at: https://doi.org/10.1007/978-94-0110027-4_2. Accessed on June 20, 2020.

Nappo R.W. and Ross, E.A. (2020). Improved outpatient haemodialysis adequacy using queued schedules. Journal of Renal Care, 46(1):62 - 68.

Nwaneri, S.C. and Anyaeche, C.O. (2018). Application of Time-Cost-Quality-Risk Trade-off Model in Magnetic
Resonance imaging machine installation project. Nigerian Journal of Technology, 37(2): $387-396$.

Odubanjo M.O.; A.O. Oluwasola and S. Kadiri (2011). The epidemiology of end-stage renal disease in Nigeria: The way forward. International Urology and Nephrology, 43(3):785-792.

Oche, M.O. and Adamu, H. (2013). Determinants of patient waiting time in the general outpatient department of a tertiary health institution in North Western Nigeria. Annals of Medical and Health Science Research, 3(4):588 - 592.

Rossiter C.E. and Raynolds, F.A. (1968). Automatic monitoring of the time waited in an outpatient clinic. Journal Storage: Med Care. 1:218-25.

Samar A. E.; B. Davide; D. Graziella; D. Evangelia; T. Giovanni and Z. Carmine (2016). Prevalence and burden of chronic kidney disease among the general population and high-risk groups in Africa: a systematic review. Available online at:https://bmjopen.bmj.com/content/8/1/e015069.info. Accessed on March 22, 2020.

Sethi S.K.; V. Krishnappa; N. Nangethu; P. Nemer; L.A. Frazee and R. Raina (2018). Antibiotic Dosing in Sustained Low-Efficiency Dialysis in Critically Ill Patients. Available online at: https://www.ncbi.nlm.nih.gov/pmc/articles/PMC6088477/. Accessed on December 30, 2020.

Stecz W.; R. Pytlak K. Rymarz and S. Niemczyk (2019). Application of Dynamic Optimisation for planning for planning a haemodialysis process. Available online at:https://doi.org/10.1186/s12882-019-1409-8. Accessed on June 5, 2020.

Zhang S.; H. Morgenstem; P. Albertus; B.K. Nallamothu; K. He and R. Saran (2019). Emergency Department visits and hospitalizations among haemodialysis patients by day of the week and dialysis schedule in the United States. Available online at: https://doi.org/10.1371/journal.pone.0220966. Accessed on June 5, 2020. 
Appendix A: Scheduling time of various processes and optimised LOS.

\begin{tabular}{|c|c|c|c|c|c|c|c|}
\hline $\mathbf{S} / \mathbf{N}$ & $A_{t}$ & $P_{t p}$ & Access Route & $D_{t p}$ (minutes) & $\mathbf{P D}_{\mathrm{tp}}$ (minutes) & Departure Time & LOS (actual) \\
\hline 1 & 8:00 & 5 & IJ & 240 & 25 & $12: 30$ & 270 \\
\hline 2 & 8:00 & 7 & IJ & 240 & 51 & $12: 58$ & 298 \\
\hline 3 & 8:05 & 5 & Fistula & 180 & 40 & $11: 25$ & 225 \\
\hline 4 & $8: 20$ & 5 & Fistula & 240 & 17 & $12: 42$ & 262 \\
\hline 5 & $8: 30$ & 30 & Femoral & 240 & 38 & $13: 38$ & 308 \\
\hline 6 & $8: 45$ & 3 & Fistula & 240 & 50 & $13: 38$ & 293 \\
\hline 7 & $8: 47$ & 10 & $\mathrm{IJ}$ & 240 & 63 & $14: 00$ & 313 \\
\hline 8 & $8: 49$ & 11 & IJ & 240 & 40 & $13: 40$ & 291 \\
\hline 9 & $8: 55$ & 15 & IJ & 240 & 25 & $13: 35$ & 280 \\
\hline 10 & $10: 15$ & 10 & IJ & 240 & 24 & $14: 49$ & 274 \\
\hline 11 & $14: 25$ & 5 & Fistula & 240 & 89 & 19:59 & 334 \\
\hline 12 & $15: 25$ & 7 & Fistula & 240 & 38 & $20: 10$ & 285 \\
\hline 13 & 8:00 & 5 & Fistula & 240 & 65 & $13: 10$ & 310 \\
\hline 14 & $8: 30$ & 5 & IJ & 180 & 63 & $12: 38$ & 248 \\
\hline 15 & $8: 30$ & 30 & Femoral & 240 & 40 & $13: 40$ & 310 \\
\hline 16 & $8: 45$ & 3 & Fistula & 240 & 97 & $14: 25$ & 340 \\
\hline 17 & 9:00 & 10 & IJ & 240 & 40 & $13: 50$ & 290 \\
\hline 18 & $13: 20$ & 11 & IJ & 360 & 54 & $20: 25$ & 425 \\
\hline 19 & $13: 30$ & 15 & IJ & 240 & 20 & 18:05 & 275 \\
\hline 20 & $14: 58$ & 10 & IJ & 180 & 32 & $18: 40$ & 222 \\
\hline 21 & $7: 50$ & 5 & Fistula & 240 & 65 & $12: 55$ & 310 \\
\hline 22 & 8:00 & 7 & Fistula & 240 & 33 & $12: 40$ & 280 \\
\hline 23 & 8:00 & 5 & Fistula & 240 & 53 & $12: 58$ & 298 \\
\hline 24 & 8:05 & 5 & Fistula & 180 & 15 & $11: 25$ & 200 \\
\hline 25 & $8: 45$ & 30 & Femoral & 240 & 23 & $13: 38$ & 293 \\
\hline 26 & $8: 47$ & 3 & Fistula & 240 & 67 & 14:00 & 310 \\
\hline 27 & $8: 30$ & 10 & IJ & 180 & 58 & $12: 38$ & 248 \\
\hline 28 & $8: 40$ & 11 & IJ & 240 & 62 & $13: 53$ & 313 \\
\hline 29 & 11:00 & 15 & IJ & 180 & 0 & $14: 15$ & 195 \\
\hline 30 & $11: 10$ & 10 & IJ & 240 & 22 & $15: 42$ & 272 \\
\hline 31 & $12: 00$ & 5 & Fistula & 240 & 22 & $16: 17$ & 267 \\
\hline 32 & 13:00 & 7 & Fistula & 240 & 79 & $18: 28$ & 326 \\
\hline 33 & 14:00 & 5 & Fistula & 180 & 18 & $17: 23$ & 203 \\
\hline 34 & $7: 50$ & 5 & Fistula & 240 & 20 & $12: 15$ & 265 \\
\hline 35 & $8: 10$ & 30 & Femoral & 240 & 54 & $13: 34$ & 324 \\
\hline 36 & $8: 15$ & 3 & Fistula & 360 & 77 & $15: 35$ & 440 \\
\hline 37 & $8: 17$ & 10 & IJ & 240 & 44 & $13: 11$ & 294 \\
\hline 38 & $8: 30$ & 11 & IJ & 180 & 71 & $12: 52$ & 262 \\
\hline 39 & $9: 15$ & 15 & IJ & 240 & 22 & $13: 48$ & 273 \\
\hline 40 & $9: 20$ & 10 & IJ & 240 & 90 & $15: 00$ & 340 \\
\hline 41 & 13:00 & 5 & Fistula & 240 & 45 & $17: 50$ & 290 \\
\hline 42 & 7:00 & 7 & Fistula & 180 & 98 & $11: 45$ & 285 \\
\hline 43 & $7: 10$ & 5 & Fistula & 240 & 60 & $12: 15$ & 305 \\
\hline 44 & $7: 12$ & 5 & Fistula & 240 & 31 & $11: 48$ & 276 \\
\hline 45 & $7: 40$ & 30 & Femoral & 360 & 143 & $14: 53$ & 433 \\
\hline 46 & $10: 40$ & 3 & Fistula & 180 & 77 & $15: 00$ & 260 \\
\hline 47 & 11:00 & 10 & IJ & 240 & 37 & $15: 47$ & 287 \\
\hline 48 & 13:00 & 11 & IJ & 240 & 69 & $18: 20$ & 320 \\
\hline 49 & $13: 15$ & 15 & IJ & 240 & 27 & $17: 57$ & 282 \\
\hline 50 & $14: 00$ & 5 & Fistula & 240 & 35 & $18: 40$ & 280 \\
\hline 51 & 8:05 & 15 & IJ & 240 & 51 & 13:11 & 306 \\
\hline 52 & $8: 15$ & 7 & Fistula & 240 & 25 & $12: 47$ & 272 \\
\hline 53 & $8: 20$ & 5 & Fistula & 180 & 22 & $11: 47$ & 207 \\
\hline 54 & $8: 22$ & 5 & Fistula & 240 & 20 & $12: 47$ & 265 \\
\hline 55 & $8: 32$ & 20 & Femoral & 240 & 63 & $13: 55$ & 323 \\
\hline 56 & $8: 45$ & 13 & IJ & 240 & 5 & $13: 23$ & 258 \\
\hline 57 & $8: 47$ & 10 & IJ & 240 & 75 & $14: 12$ & 325 \\
\hline 58 & $8: 50$ & 21 & Femoral & 240 & 30 & $13: 41$ & 291 \\
\hline 59 & $8: 55$ & 15 & IJ & 240 & 28 & $13: 40$ & 285 \\
\hline 60 & $10: 25$ & 10 & IJ & 240 & 49 & $15: 24$ & 299 \\
\hline 61 & $14: 27$ & 15 & IJ & 240 & 84 & 20:06 & 339 \\
\hline 62 & $15: 37$ & 7 & Fistula & 240 & 50 & $20: 32$ & 297 \\
\hline 63 & 8:05 & 5 & Fistula & 240 & 38 & $12: 48$ & 283 \\
\hline 64 & $8: 30$ & 12 & IJ & 180 & 38 & $12: 20$ & 230 \\
\hline 65 & $8: 35$ & 30 & Femoral & 240 & 50 & $13: 55$ & 320 \\
\hline 66 & $8: 45$ & 3 & Fistula & 240 & 50 & $13: 38$ & 293 \\
\hline 67 & 9:05 & 10 & IJ & 240 & 45 & $14: 00$ & 295 \\
\hline 68 & $11: 27$ & 11 & IJ & 360 & 40 & $18: 18$ & 411 \\
\hline 69 & $13: 40$ & 13 & IJ & 180 & 30 & $19: 03$ & 223 \\
\hline 70 & $14: 58$ & 10 & IJ & 180 & 75 & $19: 23$ & 265 \\
\hline
\end{tabular}




\begin{tabular}{|c|c|c|c|c|c|c|c|}
\hline $\mathbf{S} / \mathbf{N}$ & $A_{t}$ & $P_{t p}$ & Access Route & $\begin{array}{c}D_{t p} \\
\text { (minutes) }\end{array}$ & $\mathbf{P D}_{\text {tp }}$ (minutes) & Departure Time & LOS (actual) \\
\hline 71 & $7: 55$ & 5 & Fistula & 240 & 35 & $12: 30$ & 280 \\
\hline 72 & $8: 00$ & 7 & Fistula & 240 & 51 & $12: 58$ & 298 \\
\hline 73 & $8: 10$ & 10 & IJ & 240 & 40 & $13: 00$ & 290 \\
\hline 74 & $8: 30$ & 5 & Fistula & 180 & 20 & $11: 55$ & 205 \\
\hline 75 & $8: 45$ & 20 & Femoral & 240 & 46 & $13: 51$ & 306 \\
\hline 76 & $8: 47$ & 6 & Fistula & 240 & 35 & $13: 28$ & 281 \\
\hline 77 & $8: 30$ & 10 & IJ & 180 & 60 & $12: 40$ & 250 \\
\hline 78 & $8: 40$ & 11 & IJ & 240 & 55 & $13: 46$ & 306 \\
\hline 79 & 11:05 & 15 & IJ & 180 & 45 & $15: 05$ & 240 \\
\hline 80 & $11: 10$ & 10 & IJ & 240 & 38 & $15: 58$ & 288 \\
\hline 81 & $12: 00$ & 5 & Fistula & 240 & 12 & $16: 17$ & 257 \\
\hline 82 & $13: 35$ & 7 & Fistula & 240 & 58 & 18:40 & 305 \\
\hline 83 & $14: 00$ & 5 & Fistula & 180 & 30 & $17: 35$ & 215 \\
\hline 84 & $7: 55$ & 5 & Fistula & 240 & 70 & $13: 10$ & 315 \\
\hline 85 & $8: 10$ & 30 & Femoral & 240 & 65 & $13: 45$ & 335 \\
\hline 86 & $8: 15$ & 13 & IJ & 360 & 40 & $15: 08$ & 413 \\
\hline 87 & $8: 17$ & 10 & IJ & 240 & 37 & 13:04 & 287 \\
\hline 88 & $8: 30$ & 11 & IJ & 180 & 74 & $12: 55$ & 265 \\
\hline 89 & 9:05 & 15 & IJ & 240 & 50 & $14: 10$ & 305 \\
\hline 90 & $9: 20$ & 10 & IJ & 240 & 25 & 13:55 & 275 \\
\hline 91 & $13: 40$ & 5 & Fistula & 240 & 83 & 19:08 & 328 \\
\hline 92 & $7: 05$ & 7 & Fistula & 180 & 75 & $11: 27$ & 262 \\
\hline 93 & $7: 30$ & 5 & Fistula & 240 & 65 & $12: 40$ & 310 \\
\hline 94 & $7: 42$ & 5 & Fistula & 240 & 65 & $12: 52$ & 310 \\
\hline 95 & $7: 50$ & 20 & Femoral & 360 & 45 & $14: 55$ & 425 \\
\hline 96 & $10: 40$ & 3 & Fistula & 180 & 48 & $14: 31$ & 231 \\
\hline 97 & $11: 00$ & 10 & IJ & 240 & 40 & $15: 50$ & 290 \\
\hline 98 & 13:00 & 11 & IJ & 240 & 32 & $17: 43$ & 283 \\
\hline 99 & $13: 15$ & 15 & IJ & 240 & 80 & 18:50 & 335 \\
\hline 100 & $13: 30$ & 10 & IJ & 240 & 30 & 18:10 & 280 \\
\hline
\end{tabular}

